\title{
Analysis of Evolution Characteristics of Provincial Potential Generation Index in Mainland China*
}

\author{
Cheng Wang \\ School of International Tourism and Business Administration \\ Lijiang Tourism Research Center \\ Lijiang Teachers College \\ Lijiang, China 674199
}

\begin{abstract}
With the concept on CPGI proposed by Hudman \& L.E., and with the calculation method of PPGI to measure PPGI of PLAR in Mainland China, this study comprehensively uses the "Hu line" and Arc GIS 10.1 classification tool to reveal the spatio-temporal evolution characteristics of PPGI of PLAR in Mainland China. The results present that China's PPGI distribute as "high southeast, low northwest" from southeast to northwest, a significant spatial distribution of "Hu line". Furthermore, PPGI in Mainland China contains convergent evolution characteristics.
\end{abstract}

Keywords-evolution characteristics; PPGI; Hu line; PLAR; Mainland China; tourism demand

\section{INTRODUCTION}

The study on tourism demand of foreign tourism scholars began in the 1960s [1]. From the 1960s to the beginning of the 21 st century, there were many representative studies. Hudman \& L.E. (1979, 1980) proposed the concept of country potential generation index (CPGI for short) [2] [3]. Divisekera S (2003) explored international tourism demand model [4]. Suh, et al (2004) studied tourism preferences of leisure tourists and business travelers in Europe, North America and Japan [5]. Tran, et al (2006) pointed out that there was a positive correlation between risk travel preferences and achievement needs [6]. Lee, et al. (2007) argued that Koreans who migrated to Australia had higher travel rates and had longer travel time than that of local Korean residents [7]. Chris Cooper, et al (2010) conducted a systematic research on CPGI when discussing tourism demand [8]. In general, foreign research literature mainly focuses on theoretical exploration and case studies of tourism demand models and tourism demand forecasting.

China's research on tourism demand began in the 1980s [1], nearly 20 years later than abroad. In the 20th century, relevant researches are gradually deepened and promoted. There emerged some representative studies as the following: Xie Yanjun (2004) systematically studied tourism demand from two aspects, including influential factors on tourism demand and objective obstacles preventing the realizing of tourism demand [9]. Feng Xuegang, et al. (2009) specifically

*Fund Project: National natural science fund projects of China (41361037, 41671147) answered the current strategic problem of tourism industry's potential development through measuring methods [10]. Wu Bihu, et al (2010) reviewed the theory and technology of tourism demands, and predicted with quantitative method to analyze tourist market space and tourist demand [11]. Based on the tourism demand survey data of 2014 "Golden Week" of the Spring Festival, Yang yong (2016) explored the impact of social interaction and tourism context on tourism demand [12]. Jiang Yiyi, et al (2017) constructed an outbound tourism demand model [13].

Ma Lijun, et al (2017) analyzed the spatial and temporal characteristics of tourism demand of residents in Hunan Province based on network attention [14].

In general, the domestic research literature mainly focuses on the statistical description of tourism demand, and rarely uses the model to carry out the study and mechanism analysis. Compared with foreign research, the research is scattered and not systematic enough, and the research conclusion does not have universal guiding significance [15].

When sorting out the literature, it has been found that the research results in the field of tourism demand are fruitful. However, there are few researches on the important part of tourism demand - the potential generation index and it is not common to study on the potential generation index from the provincial administrative level. It could be believed that it is particularly necessary to conduct an in-depth study on provincial potential generation index (PPGI for short).

\section{RESEARCH REGION AND DATA SOURCE}

\section{A. Research Region}

Considering the availability and completeness of the data, the three provincial-level administrative regions of China: Hong Kong, Macao and Taiwan are not included because of lack of collected number about domestic and foreign tourists in the past years.

Finally 31 provincial-level administrative regions (PLAR for short) were selected as the study objects in Mainland China. They are divided into two sections from geographic perspective: (1) the southeast section, includes PLAR as the following: Heilongjiang, Jilin, Liaoning, Beijing, Tianjin, Hebei, Henan, Shandong, Shanxi, Shaanxi, Jiangsu, Anhui, 
Shanghai, Zhejiang, Jiangxi, Fujian, Hunan, Hubei, Guangdong, Guangxi, Chongqing, Guizhou, Yunnan and Hainan; (2) the northwest section, includes PLAR as the following: Inner Mongolia, Xinjiang, Ningxia, Gansu, Qinghai, Tibet and Sichuan.

\section{B. Data Source}

In order to better the observation of the latest evolution of PPGI in Mainland China, four time- sections (i.e. 2002, 2007, 2012, 2017) of PLAR were selected to study and compare. Relying on China's statistical information network, this study inquiries about the national economic and social development bulletins of PLAR respectively, and chooses the four time-sections to generate the data of domestic and foreign tourists and the indicators of resident population, then concludes sample data (Due to the limitations, the sample data list is omitted.)

\section{RESEARCH METHODS}

\section{A. CPGI and PPGI Calculation Method}

Hudman, L.E. (1979, 1980) put forward CPGI [2] [3], and the calculation method is shown as Equation 1:

Equation 1: $\mathrm{CPGI}=\left(\mathrm{N}_{\mathrm{e}} / \mathrm{N}_{\mathrm{w}}\right) /\left(\mathrm{P}_{\mathrm{e}} / \mathrm{P}_{\mathrm{w}}\right)$

In the formula: $\mathrm{N}_{\mathrm{e}}$ - the number of tourists in the state; $\mathrm{N}_{\mathrm{w}}$ - the number of tourists in the world; $\mathrm{P}_{\mathrm{e}}-$ the population of the country; $\mathrm{P}_{\mathrm{w}}$ - the population of the world.

$\mathrm{CPGI} \geqq 1$ indicates the average generation capacity of the country's potential tourism. CPGI $<1$ indicates that the ability to generate tourists is lower than the average.

CPGI means the average national generation capacity, that is, the ability to evaluate tourism in a country. It has immediate significance of reference [8] [16]. The above formula was originally used for comparing potential generation index between countries. It can also be used to compare the ability of generating tourism among different PLAR [11]. It is believed that CPGI calculation formula can be used to measure the potential generation capacity of a country's PLAR. Furthermore, the comparison of PPGI in a country could be conducted and its evolution characteristics could be explored. According to the availability and comparability of data, when measuring PPGI of PLAR of a country, the number of tourists at home and abroad may be used to replace the number of tourists. The PPGI algorithm is as follows:

\section{Equation 2: $\mathrm{PPGI}=\left(\mathrm{N}_{\mathrm{p}} / \mathrm{N}_{\mathrm{e}}\right) /\left(\mathrm{P}_{\mathrm{p}} / \mathrm{P}_{\mathrm{e}}\right)$}

In the formula: $\mathrm{N}_{\mathrm{p}}$ - the number of tourists in a certain province of a country receiving domestic and foreign tourists; $\mathrm{N}_{\mathrm{e}}$ - the number of tourists generated in a certain country; $\mathrm{P}_{\mathrm{p}}$ - the population of a province in a country; $\mathrm{P}_{\mathrm{e}}-$ the population of a country.

PPGI $\geqq 1$ indicates the average capacity to generate tourists in a certain province. PPGI $<1$ indicates that the ability to generate tourists in a certain province is lower than the average.
Substituting the sample data into Equation 2, the results of PPGI in Mainland China are obtained (see "Table I").

TABLE I. RESUlTS OF PPGI IN MAINLAND CHINA FROM 2002 TO 2017

\begin{tabular}{|l|l|l|l|l|}
\hline \multicolumn{1}{|c|}{ PLAR } & \multicolumn{1}{c|}{$\mathbf{2 0 0 2}$} & \multicolumn{1}{c|}{$\mathbf{2 0 0 7}$} & $\mathbf{2 0 1 2}$ & $\mathbf{2 0 1 7}$ \\
\hline Beijing & 7.04 & 4.01 & 2.21 & 1.46 \\
\hline Shanghai & 5.74 & 2.66 & 2.11 & 1.46 \\
\hline Tianjin & 3.20 & 2.52 & 1.49 & 1.29 \\
\hline Liaoning & 1.29 & 1.77 & 1.62 & 1.24 \\
\hline Heilongjiang & 0.77 & 0.79 & 1.29 & 0.47 \\
\hline Jilin & 0.78 & 0.62 & 0.63 & 0.76 \\
\hline Shandong & 0.91 & 0.98 & 0.99 & 0.76 \\
\hline Shanxi & 1.13 & 1.15 & 1.03 & 1.63 \\
\hline Henan & 0.56 & 0.79 & 0.66 & 0.66 \\
\hline Hebei & 0.76 & 0.66 & 0.62 & 0.82 \\
\hline Hunan & 0.74 & 0.78 & 0.89 & 1.05 \\
\hline Hubei & 0.96 & 0.82 & 1.16 & 1.04 \\
\hline Jiangsu & 1.18 & 1.41 & 1.15 & 1.00 \\
\hline Jiangxi & 0.66 & 0.73 & 0.89 & 1.34 \\
\hline Zhejiang & 1.51 & 1.76 & 1.42 & 1.22 \\
\hline Fujian & 1.01 & 1.05 & 0.87 & 1.05 \\
\hline Anhui & 0.53 & 0.59 & 0.96 & 1.08 \\
\hline Guangdong & 1.00 & 0.70 & 1.15 & 0.43 \\
\hline Guangxi & 0.89 & 0.83 & 0.78 & 1.15 \\
\hline Shaanxi & 0.89 & 0.99 & 1.21 & 1.47 \\
\hline Hainan & 1.33 & 0.98 & 0.73 & 0.78 \\
\hline Yunnan & 1.03 & 0.95 & 0.85 & 1.31 \\
\hline Guizhou & 0.49 & 0.71 & 1.19 & 2.23 \\
\hline Sichuan & 0.71 & 1.05 & 1.07 & 0.87 \\
\hline Chongqing & 1.28 & 1.303 & 0.44 & 1.89 \\
\hline Ningxia & 0.47 & 0.54 & 0.41 & 0.34 \\
\hline Gansu & 0.34 & 0.42 & 0.59 & 0.98 \\
\hline Qinghai & 0.67 & 0.83 & 0.54 & 0.62 \\
\hline Tibet & 0.29 & 0.63 & 0.65 & 0.82 \\
\hline Xinjiang & 0.45 & 0.49 & 0.43 & 0.49 \\
\hline Inner Mource: The data in "Table 1 "is obtained by the author using Equation. \\
\hline Total & 0.43 & 0.58 & 0.48 & 0.49 \\
\hline The average & 39.04 & 34.094 & 30.51 & 32.2 \\
\hline & 1.26 & 1.09 & 0.98 & 1.04 \\
\hline & & & \\
\hline
\end{tabular}

\section{B. Hu Line Reference Method}

In 1935, Hu Huanyong published the paper "Essays on China's Population Distribution" in the Journal of Acta Geographica Sinica, which collected and compiled the population data of various regions of the country, and accurately recorded the population data to the county-level unit scale, and mapped out the first population distribution in China and the population density map. For the first time, he revealed the fact through quantitative method that China's population is unevenly distributed, and proposed the famous geographical boundary line of Aihui of Heilongjiang province - Tengchong of Yunnan province [17] [18]. The proposal of Hu Huanyong's line is of great significance. The first quantitative description of the spatial characteristics of the Chinese population reveals the fact that there is a huge disparity in the population density between the southeast section and the northwest section. It is known as the "Hu line". [19] Studies have shown that the Hu line is actually a dividing line of the Chinese landscape. Then, is there a huge disparity in PPGI between the southeastern section and the northwestern section in Mainland China? Or is there a 
distribution law of $\mathrm{Hu}$ line? In order to answer the above questions, the "Hu line" is used as a reference to observe the evolution and spatial distribution pattern of PPGI in Mainland China.

\section{Arc GIS Method}

In order to reveal the evolution and spatial distribution of PPGI in Mainland China more effectively, a vertical Chinese map (Review No.: GS (2016) 2893) supervised by the National Surveying and Mapping Geographic Information Bureau is used as the base map. A vector map was drawn with a ratio of 1: 25 million according to a base map, and "Hu line" was labeled on each map. PPGI data of PLAR from four time-sections was imported into Arc GIS 10.1 China map data table, and the four-year PPGI was divided into two levels by using the Arc GIS 10.1 classification tool. The Spatial distribution of PPGI in Mainland China from 2002 to 2017 was finally drawn (see "Fig. 1" "Fig. 2" "Fig. 3" "Fig. 4").

\section{ANALYSIS OF EVOLUTION CHARACTERISTICS OF PPGI IN MAINLAND CHINA}

\section{A. PPGI in Mainland China Shows the Spatial Distribution} Characteristics of "High-southeast and Low-northwest" from the Southeast to the Northwest

In "Fig. 1" "Fig. 2" "Fig. 3" "Fig. 4", from a spatial point of view, PPGI in Mainland China is characterized by "highsoutheast and low-northwest" from the southeast to the northwest, which indicates that it has a significant spatial distribution of the "Hu Line". The provinces of PPGI $\geqq 1$ are distributed in the southeast section of the "Hu Line", while the provinces in the northwest section of the "Hu Line" are all PPGI $<1$, which implies that PPGI on both sides of the "Hu Line" is distinctly different. From the southeast to the northwest, the PPGI tends to be smaller overall. From a perspective of time, from 2002 to 2017, high PPGI and low PPGI distribution areas in Mainland China are relatively stable. In general, there are some changes in the distribution area of PPGI $\geqq 1$. However, it is mainly in the southeastern parts. And the distribution area of PPGI $\geqq 1$ evolves from small clusters or strips to clumps. The distribution area of PPGI $<1$ shows the gradual decrease in the southeast and a relatively stable distribution pattern in the northwest.

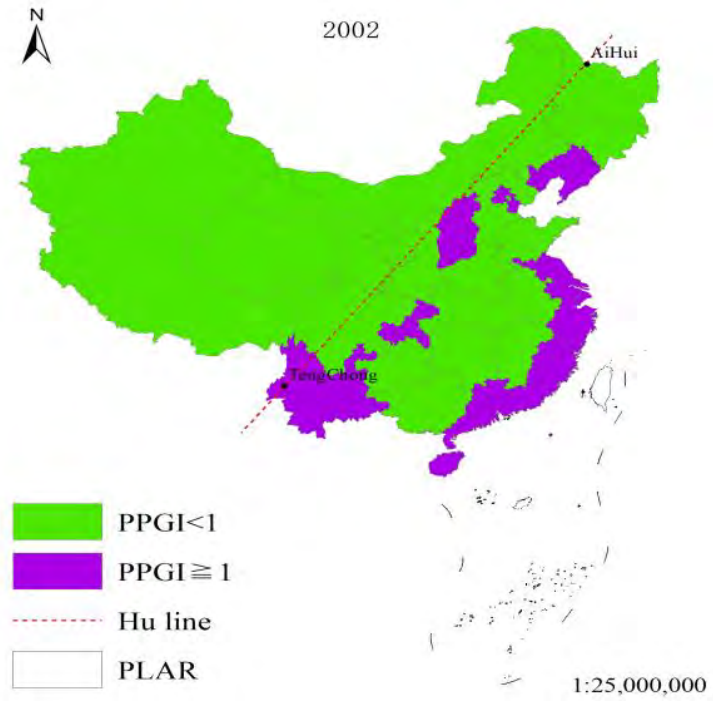

Fig. 1. Spatial distribution of PPGI in Mainland China from 2002 to 2017.(a).

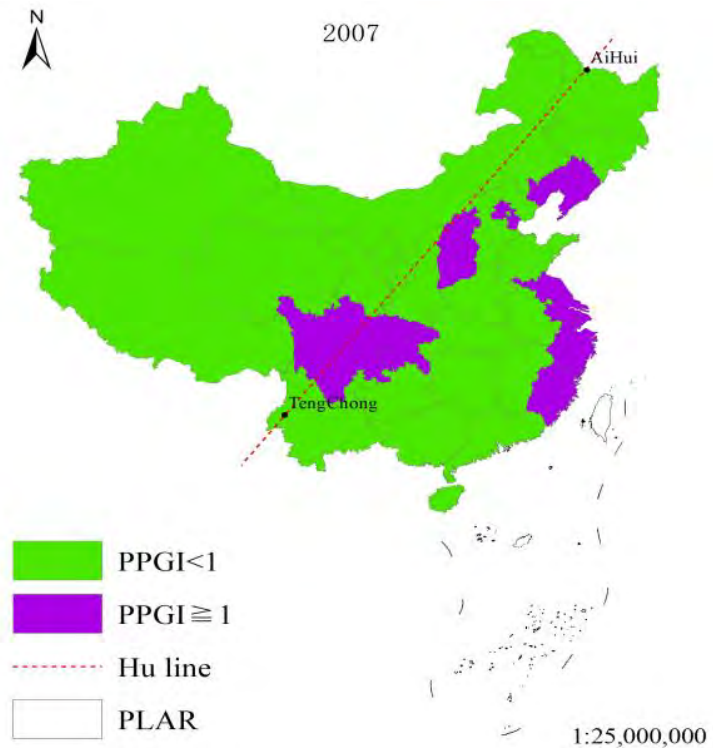

Fig. 2. Spatial distribution of PPGI in Mainland China from 2002 to 2017.(b). 


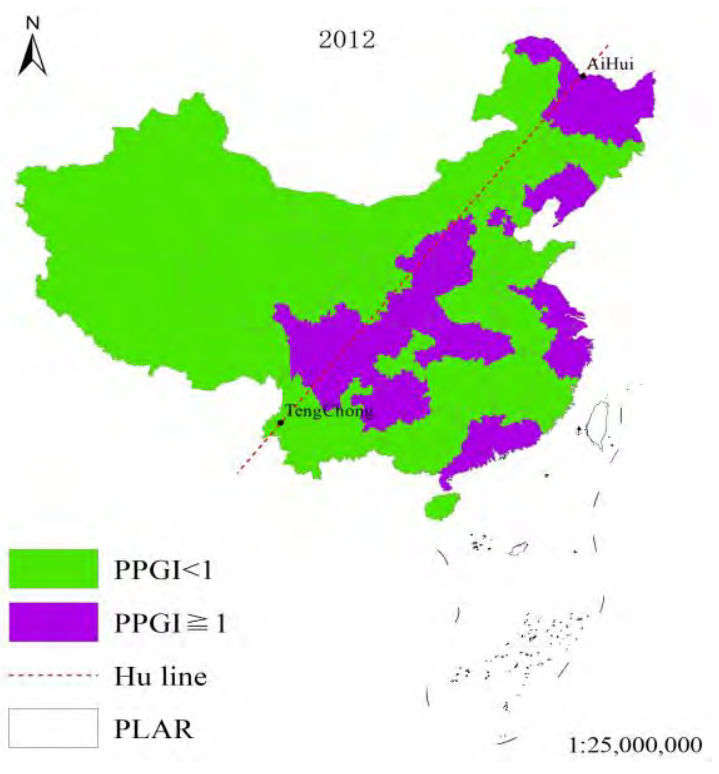

Fig. 3. Spatial distribution of PPGI in Mainland China from 2002 to 2017.(c).

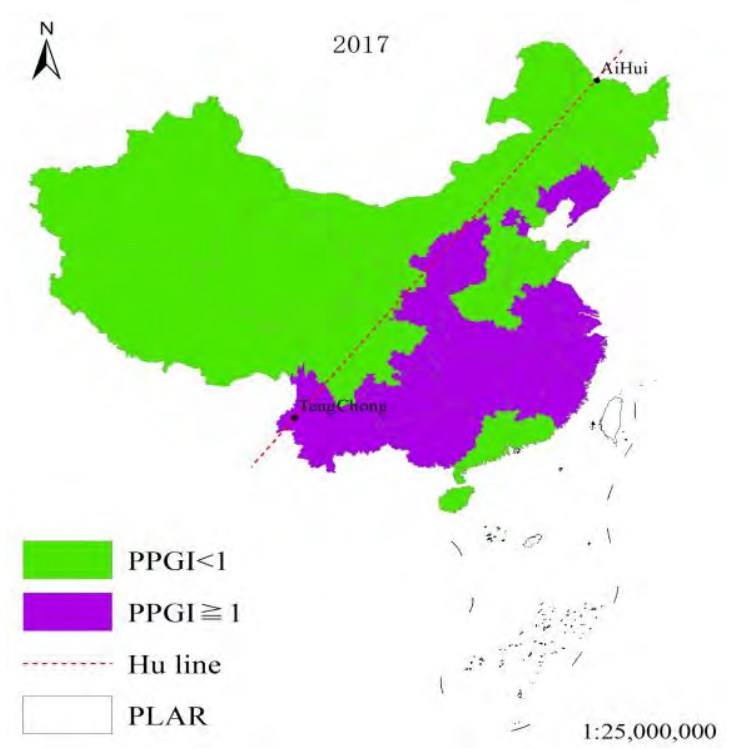

Fig. 4. Spatial distribution of PPGI in Mainland China from 2002 to 2017.(d).

\section{B. PPGI Shows the Characteristics of Convergence Evolution in Mainland China}

Results have been reached as below from the perspective of the average value of PPGI: there were 7 of PLAR in Mainland China with PPGI higher than the average in 2002. In 2007, 8 of PLAR are higher than the average; in 2012, 14 of PLAR are higher than the average. In 2017, 15 of PLAR are higher than the average. Obviously, the number of PLAR of higher PPGI is gradually increasing.

From the comparison of the maximum index and the minimum index of each time section, in 2002, Beijing had the largest PPGI, 24.28 times higher than the minimum PPGI (Tibet). In 2007, Beijing had the largest PPGI, 9.55 times higher than the smallest PPGI (Gansu). In 2012, Beijing has the largest PPGI, 5.39 times higher than the minimum PPGI (Ningxia). In 2017, Guizhou has the largest PPGI, 6.55 times higher than the smallest PPGI (Ningxia). From the comparison between the maximum index and the minimum index of the four time sections, it can be concluded that the multiple between the maximum index and the minimum index is reduced.

Thus a conclusion can be drawn that the number of PLAR with higher PPGI in Mainland China increase successively and the gap becomes smaller between the maximum and minimum PPGI, indicating that the evolution of PPGI has the character of convergence in Mainland China.

\section{CONCLUSION AND DiscUSSION}

\section{A. Conclusion}

This paper takes CPGI theory as references and uses PPGI calculation method to measure PPGI of PLAR in Mainland China. Using the reference method of "Hu line" and Arc GIS 10.1 classification tool, this paper reveals the time-space evolution characteristics of PPGI of PLAR in mainland China. The main conclusions are as follows:

Firstly, CPGI can be used to measure the potential generation ability among different PLAR in a certain country.

Secondly, PPGI in Mainland China has characteristics of "high southeast, low northwest" from the southeast to the northwest, a significant spatial distribution of "Hu line".

Thirdly, PPGI in Mainland China is characterized by convergence.

\section{B. Discussion}

This paper conducts the first measurement of PPGI in Mainland China, which analyzes the temporal and spatial evolution characteristics of PPGI of PLAR. The investigation of the influential factors should be the focus of future research. The use of the number of reception tourists, instead of the number of generation tourists, may result in a higher PPGI might be produced, when the received tourists take the place of generated tourists, and more effective measures should be taken to study and solve this issue. It is believed that the inconsistency of tourism data statistics, incomplete tourism data statistics, and low accuracy of tourism data have become major obstacles to prevent highquality tourism research. Hence, dialogues, cooperation and researches among tourism academic communities are in urgent need to search practical and feasible solutions, to promote scientific study and sustainable development of tourism and finally contribute to a community with a shared future for mankind.

\section{ACKNOWLEDGMENT}

In the process of making "Fig. 1", Liu Anle, a lecturer at the Liupanshui Normal University in Guizhou, and a 2018 doctoral student at Yunnan University of Finance and Economics, provided technical support of Arc GIS 10.1. 
In the process of revision, Luo Huifan, a lecturer at the Lijiang Teachers College in Yunnan did a proofreading work.

\section{REFERENCES}

[1] Ouyang Runping, $\mathrm{Hu}$ Xiaoqin. A Literature Review of Tourism Demand Study Home and Abroad[J]. Journal of Nanjing University of Finance and Economics, 2007(3): 80-83.

[2] Hudman, L.E. Origin Regions of International Tourism [M]. In Sinnhuber, K.A., \& Julg, F., (Hrsg.), Wiener Geographische. 1979:43-49.

[3] Hudman, L.E. Tourism: A shrinking world[M]. Columbus: Grid Inc., 1980.

[4] Divisekera S. A model of demand for international tourism [J]. Annals of Tourism Research, 2003(1): 31-49.

[5] Suh Y K, W C Gartner. Preferences and trip expenditures - a conjoint analysis of visitors to Seoul, Korea [J]. Tourism Management, 2004(25):127-137.

[6] Tran X, L.Ralston. Tourism preferences: Influence of unconscious needs[J]. Annals of Tourism Research, 2006(2):424-441.

[7] Lee S H, B S parks. Cultural influences on travel life style: A comparison of Korean Australians and Koreans in Korea [J]. Tourism Management, 2007(28):505-518.

[8] Chris Cooper, John Fletcher, et al. Tourism: Principles and Practice (Fourth Edition) $[\mathrm{M}]$. China: Dongbei University of Finance \& Economics Press, 2010:41.

[9] Xie Yanjun. Basic Tourism Science [M]. Beijing: China Tourism Press, 2004: 171-185.

[10] Feng Xuegang, Wang Qiongying. Evaluation Model and Empirical Analysis of China's Tourism Industry Potential [J]. Chinese Journal of Management Science, 2009(4):178-184.

[11] Wu Bihu, Yu Xi. Principles of Tourism Planning [M]. Beijing: China Tourism Press, 2010: 79-97.

[12] Yang Yong. Research on the Influence of Social Communication and Tourism Situation on Tourism Demand - Based on the Empirical Analysis on the Golden Week of the Spring Festival[J]. Tourism Tribune, 2016(10):56-69.

[13] Jiang Yiyi, Liu Xiangyan, Song Huilin. Influencing Factors of Outbound Tourism Demand - On the Similarities and Differences between Developing and Developed Economies[J]. Tourism Tribune, 2017(1):12-21.

[14] Ma Lijun, Long Yun. Temporal and spatial characteristics of tourism demand of residents in Hunan Province based on network attention[J]. Economic Geography, 2017(2):201-208.

[15] Li Junyi, Ma Yaofeng, Yang Min. A Literature Review on Demand Forecasting Methods in China's Tourism[J]. Commercial Research, 2009(3):17-20.

[16] Liang Xuecheng. Selected Readings of Frontier Works in Tourism Management [M]. Beijing: China Economic Publishing House, 2013: 28.

[17] $\mathrm{Hu}$ Huanyong.Essays on China's population distribution. Acta Geographica Sinica, 1935(2): 33-74.

[18] Lu Dadao, Wang Zheng, Feng Zhiming, et al. Academic debates on $\mathrm{Hu}$ Huanyong population line[J]. Geographical Research, 2016(5):805-824.

[19] Tien H Y. Demography in China: From zero to now. Population Index, 1981(4):683-710. 